\title{
Repair of giant postlaminectomy pseudomeningocele with fast-resorbing polymer mesh: technical report of $\mathbf{2}$ cases
}

\author{
Carlos M. Alvarez, MD, Timur M. Urakov, MD, and Steven Vanni, DO, DC \\ Department of Neurological Surgery, University of Miami Miller School of Medicine, Miami, Florida
}

Pseudomeningocele is a rare but well-known complication of lumbar spine surgery, which arises in $0.068 \%-0.1 \%$ of individuals in large series of patients undergoing laminectomy and in up to $2 \%$ of patients with postlaminectomy symptoms. In symptomatic pseudomeningoceles, surgical reexploration and repair of the dural defect are typically necessary. Whereas the goals of pseudomeningocele repair, which are extirpation of the pseudomeningocele cavity and elimination of extradural dead space, can typically be achieved by primary closure performed using nonabsorbable sutures, giant pseudomeningoceles $(>8 \mathrm{~cm}$ ) can require more elaborate repair in which fibrin glues, dural substitute, myofascial flaps, or all of the above are used. The authors present 2 cases of postsurgical symptomatic giant pseudomeningoceles that were repaired using a fast-resorbing polymer mesh-supported reconstruction technique, which is described here for the first time.

https://thejns.org/doi/abs/10.3171/2017.6.SPINE161292

KEY WORDS pseudomeningocele; dural repair; laminectomy; fast-resorbing polymer mesh; surgical technique

$\mathrm{P}$ SEUDOMENINGOCELE after lumbar spine surgery is a known complication with an estimated frequency of $0.068 \%-2 \%$ of patients who undergo laminectomy. ${ }^{16,18,19}$ Symptoms of postsurgical pseudomeningocele can include postural headache, nausea, vomiting, and-if there is nerve entrapment or mass effect-radicular symptoms or cauda equina syndrome..$^{711-14}$ Pseudomeningoceles have been classified as large or giant based on their size (>5 $\mathrm{cm}$ and $>8 \mathrm{~cm}$, respectively). ${ }^{10,20}$ There have been reports of large and giant pseudomeningoceles resolving spontaneously, but the majority of symptomatic cases require surgical reexploration and repair. ${ }^{17}$ Pseudomeningoceles with easily identifiable durotomy, even those with entrapped nerve roots, can be repaired primarily with watertight closure of the dural tear by using nonabsorbable sutures and multilayer fascial closure. ${ }^{8,15}$ For giant pseudomeningoceles, more complex surgical repair, including the procedures mentioned above and, additionally, raising the lumbar myofascial flaps and/or placement of a subarachnoid catheter for CSF flow diversion, have been demonstrated to be effective..$^{10,20}$

Fast-resorbing polymer (FRP) mesh made of polylactic or polyglycolic acid has been used routinely for temporary fixation in pediatric craniofacial cases since its approval by the FDA in 2002., ${ }^{2,5}$ Polyglycolic acid mesh has also been used with fibrin glue for nonsuture dural repair in both intra- and extradural spine surgery. ${ }^{4}$ The ability of the mesh to provide structural support to the dural repair, preventing herniation and reformation of the pseudomeningocele, made it an attractive choice for reconstruction in these cases.

The authors present 2 cases of giant postsurgical lumbar pseudomeningocele that required complex repair, which was performed using dural substitute and fibrin glue supported structurally by FRP mesh with paraspinous muscle myofascial flaps. They also review the relevant literature.

\section{Case Reports}

\section{Case 1}

History and Physical Examination

A 39-year-old man with a history of laminectomy and discectomy at L4-5 that had been performed in multiple operations at another institution, presented to a local community neurosurgeon reporting back and leg pain and numbness with neurogenic claudication. Imaging showed an L5-S1 disc herniation, for which posterior pedicle screw fixation and decompression were performed. The patient recovered uneventfully and was discharged on 


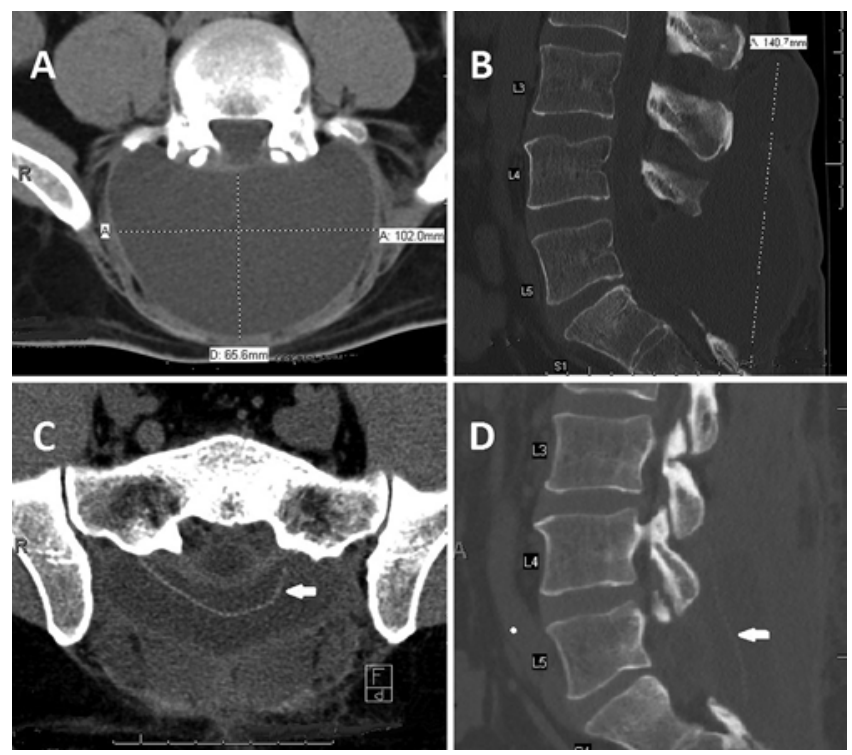

FIG. 1. Case 1. Noncontrast CT scans of the lumbar spine in axial cut (A) and sagittal cut (B), demonstrating the extent of the giant pseudomeningocele. Postoperative CT scans in axial cut (C) and sagittal cut (D), demonstrating the location of the FRP mesh (arrows) and resolution of the pseudomeningocele at 4 months after surgery.

postoperative day 4, with unremarkable follow-up findings 7 days later in the clinic. Two weeks later, the patient presented to a nearby emergency room with an abscess near the instrumentation, which interventional radiology treated by placing 2 drains under fluoroscopic guidance. The drains were removed when their output reached zero, and the patient was discharged after receiving intravenous antibiotics. The patient seemed to have improved significantly, but within 2 weeks the abscess had returned and he was transferred back to his original neurosurgeon with a clinical picture suggesting sepsis and endocarditis, necessitating removal of the posterior instrumentation and a month-long hospital stay. During the course of the drain placements for abscess and removal of hardware, an unintended durotomy was created. Once identified, the CSF leak was treated with an epidural blood patch and lumbar drainage, which failed.

The patient presented to our clinic with an extremely large pseudomeningocele occupying the space between L2-3 and S2-3, with dimensions of approximately $14 \mathrm{~cm}$ $\times 6.6 \mathrm{~cm} \times 10.2 \mathrm{~cm}($ Fig. $1 \mathrm{~A}$ and B). The patient was reporting headache, intractable back pain, and difficulty sitting up and walking. A right C1-2 drain was placed under fluoroscopic guidance to facilitate CT and MR myelography, which were used to better visualize the CSF collection prior to surgery.

\section{Operation}

The procedure was performed after induction of general anesthesia, with the patient in the prone position. Electromyography, somatosensory evoked potential, and motor evoked potential electrode monitoring were used. The previous lumbar excision was explored. On wider exposure, an extremely large, scarred, dead space was observed. The extensive pseudomeningocele sac was dissected out circumferentially down to the bone. Multiple sites of CSF leaks were evident on the dural surface, with the nerve roots scarred and tightly adhering to the wall of the pseudomeningocele, which could not be separately mobilized without nerve root damage. The pseudomeningocele wall was further elevated off the bone and sutured over the dural sac with interrupted 4-0 Prolene, laying it flat against the thecal sac to seal the CSF leak. Due to the extent of the dural tears, the thecal sac could not be primarily repaired. A piece of $60 \mathrm{~mm} \times 80 \mathrm{~mm} \times 0.75 \mathrm{~mm}$ MacroPore mesh (Medtronic) was cut to size, heated in $60^{\circ} \mathrm{C}$ saline, and molded to cover the bony defect. After a layer of collagen dural substitute was placed over this covering, the MacroPore mesh was screwed down onto the bone itself with 6 small absorbable screws (Fig. 2). Hydrogel dural sealant was then sprayed over all of the MacroPore mesh. Next, the paraspinous muscle was dissected free of the underlying subcutaneous tissue and was advanced into the midline, turned over, and sewn together with 2-0 Vicryl horizontal mattress sutures to close off the dead space. The wound was then closed with 2-0 Vicryl in the subcutaneous tissue. The skin was closed using a 3-0 Prolene horizontal mattress stitch. Three 7-mm round drains were brought out through separate stab wound incisions and connected to Jackson-Pratt bulbs set to gravity, 1 drain just over the CSF leak and 2 over the muscle.

\section{Postoperative Course}

The patient's drains were discontinued when output reached less than $50 \mathrm{ml}$ in 24 hours, and the patient was discharged without incident. Sutures were removed at the 2-week postoperative visit, with no recurrence of CSF leak. The patient's radicular symptoms persisted, necessitating interbody fusion via an anterior approach 4 months later, and there was no postoperative CSF leak. In Fig. 1, panels $\mathrm{C}$ and $\mathrm{D}$ illustrate the mesh in place and the resolution of the pseudomeningocele. 

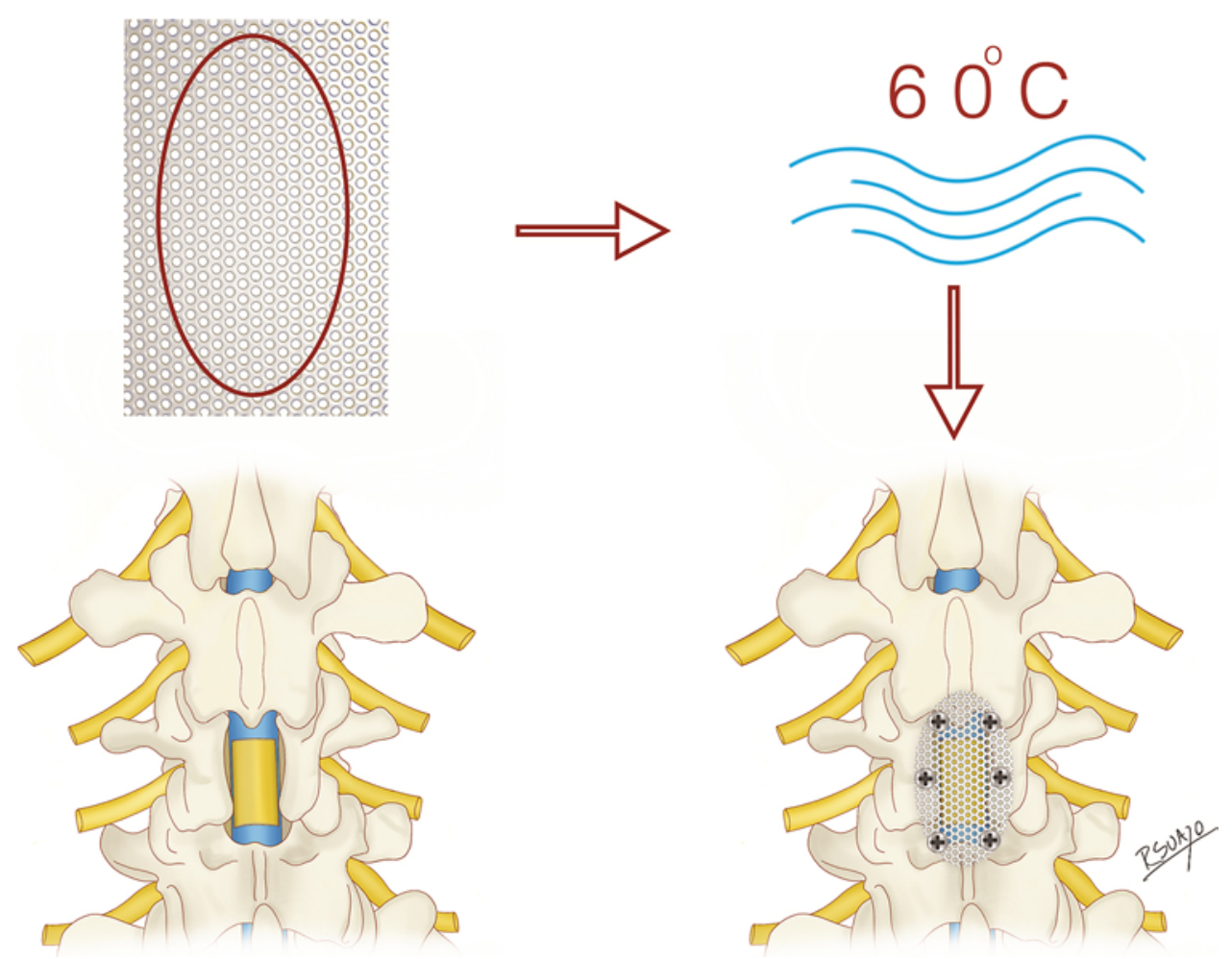

FIG. 2. Drawings illustrating how the FRP mesh, cut to size and shaped in a $60^{\circ} \mathrm{C}$ bath, is used to cover the laminectomy defect. Copyright Roberto Suazo. Published with permission. Figure is available in color online only.

\section{Case 2}

History and Physical Examination

The patient was a 92-year-old man with a history of right L3-4 and L4-5 hemilaminectomy for resection of synovial cyst at another institution. Six weeks later, the patient presented to the same institution reporting positional headache and back pain. A CSF leak was diagnosed and the patient underwent reexploration, L3-4 microdiscectomy, and repair of the unintentional durotomy. The patient's course was complicated by deep venous thrombosis. He presented to our clinic with headache, syncope, and vomiting, and was found to have a large ballotable mass at the site of the laminectomy incision. The patient was wheelchair dependent due to positional symptoms. Review of his MRI studies obtained at the other institution showed a CSF collection extending from L2-3 down to L4-5.

\section{Operation}

The procedure was performed after induction of general anesthesia, with the patient prone on a 4-poster frame. A small incision was made in the midline over the L3-4 and L4-5 level. A large fluid-filled sac containing CSF under pressure was encountered. There was a large pseudomeningocele cavity. Prior laminectomy defects on the right side were exposed. Further lateral exposure revealed CSF flowing from the lateral recess beneath the edge of the bone, especially at the L3-4 and L4-5 level, that could not be repaired primarily. The laminectomy edges were widened to define the virgin dura mater around the edges.
Hydrogel sealant and then collagen dural substitute were tucked under the edges of the laminectomy defect to seal the CSF leak. The FRP mesh was then cut to size, heated in $60^{\circ} \mathrm{C}$ saline, shaped to fit over the laminectomy defect, and secured with small resorbable screws. The wound was closed primarily by mobilization of the muscle and then suturing the muscle to both the interspinous ligaments, followed by closure of the fascia in a watertight fashion with 0 Vicryl, followed by 2-0 Vicryl sutures on the subcutaneous tissue, and 3-0 Prolene on the skin. A lumbar drain was left in place at the L3-4 level.

\section{Postoperative Course}

The patient remained flat in bed for 72 hours, after which his lumbar drain was discontinued. He recovered well and returned to ambulatory status, with no recurrence of symptoms at 6 months.

\section{Discussion}

Postoperative pseudomeningoceles are caused by durotomy, which can be intentional, as in intradural tumor resection, or unintentional. The rate of unintentional durotomy in initial lumbar surgery has been estimated to be between $3 \%$ and $5 \%$, whereas in revision surgery it can be as high as 7\%-17\%. ${ }^{1,3,6,9}$ The incidence of postsurgical pseudomeningoceles is estimated to be between $0.068 \%$ and $2 \%$, making this a relatively rare complication. . $^{16,18,19}$ The repair of small symptomatic meningoceles typically consists of watertight primary closure of the dural tear 
with Prolene or nylon sutures, and elimination of dead space with multilayer fascial closure. ${ }^{8,15}$ In giant pseudomeningoceles, myofascial flaps can be brought up to minimize dead space and decrease the risk of recurrence..$^{10}$

For cases in which the durotomy repair is complicated by a far-lateral location of dural defect or multiple defects with adherent nerve roots, simple watertight closure by approximating the edges of the dural tear can be impractical or dangerous. The cases described here were additionally complicated by large bony defects caused by previous surgery, which did not provide the necessary structural bases for the expanding thecal sac. The FRP mesh is easy to mold and can provide structural support for the collagen dural substitute, which is used in conjunction with hydrogel dural sealant. It provides not only immobilization of the dural substitute, ensuring a watertight seal, but can also serve as an anchor point for paraspinous muscle flaps. In this way, the mesh prevents herniation of the dural repair and recurrence of the pseudomeningocele. In other strategies of pseudomeningocele repair that do not include the use of mesh, structural support of the repair can be inadequate, leading to pseudomeningocele recurrence.

\section{Conclusions}

Further prospective studies comparing primary repair, repair with myofascial flaps, repair with FRP mesh, and combinations thereof are necessary to determine the superiority of this technique in terms of long-term patient outcomes. To our best knowledge, this technique has not been described before in the English-language literature. An FRP mesh-supported repair can be useful in treating giant postsurgical pseudomeningoceles in carefully selected cases.

\section{References}

1. Baker GA, Cizik AM, Bransford RJ, Bellabarba C, Konodi MA, Chapman JR, et al: Risk factors for unintended durotomy during spine surgery: a multivariate analysis. Spine $\mathbf{J}$ 12:121-126, 2012

2. Cohen SR, Mittermiller PA, Holmes RE, Broder KW: Clinical experience with a new fast-resorbing polymer for bone stabilization in craniofacial surgery. J Craniofac Surg 17:40-43, 2006

3. Guerin P, El Fegoun AB, Obeid I, Gille O, Lelong L, Luc S, et al: Incidental durotomy during spine surgery: incidence, management and complications. A retrospective review. Injury 43:397-401, 2012

4. Hida K, Yamaguchi S, Seki T, Yano S, Akino M, Terasaka $\mathrm{S}$, et al: Nonsuture dural repair using polyglycolic acid mesh and fibrin glue: clinical application to spinal surgery. Surg Neurol 65:136-143, 2006

5. Holmes RE, Cohen SR, Cornwall GB, Thomas KA, Kleinhenz KK, Beckett MZ: MacroPore resorbable devices in craniofacial surgery. Clin Plast Surg 31:393-406, v, 2004

6. Kalevski SK, Peev NA, Haritonov DG: Incidental dural tears in lumbar decompressive surgery: Incidence, causes, treatment, results. Asian J Neurosurg 5:54-59, 2010

7. Kamali R, Naderi Beni Z, Naderi Beni A, Forouzandeh M: Postlaminectomy lumbar pseudomeningocele with nerve root entrapment: a case report with review of literature. Eur J Orthop Surg Traumatol 22 (Suppl 1):S57-S61, 2012

8. Lee KS, Hardy IM II: Postlaminectomy lumbar pseudomeningocele: report of four cases. Neurosurgery 30:111114, 1992

9. McMahon P, Dididze M, Levi AD: Incidental durotomy after spinal surgery: a prospective study in an academic institution. J Neurosurg Spine 17:30-36, 2012

10. Misra SN, Morgan HW, Sedler R: Lumbar myofascial flap for pseudomeningocele repair. Neurosurg Focus 15(3):E13, 2003

11. O'Connor D, Maskery N, Griffiths WE: Pseudomeningocele nerve root entrapment after lumbar discectomy. Spine (Phila Pa 1976) 23:1501-1502, 1998

12. Oterdoom DLM, Groen RJM, Coppes MH: Cauda equina entrapment in a pseudomeningocele after lumbar schwannoma extirpation. Eur Spine J 19 (Suppl 2):S158-S161, 2010

13. Pau A: Postoperative "meningocele spurius". Report of two cases. J Neurosurg Sci 18:150-152, 1974

14. Pavlou G, Bucur SD, van Hille PT: Entrapped spinal nerve roots in a pseudomeningocoele as a complication of previous spinal surgery. Acta Neurochir (Wien) 148:215-220, 2006

15. Rocca A, Turtas S, Pirisi A, Agnetti V: Iatrogenic lumbar pseudomeningocele. Zentralbl Neurochir 47:311-315, 1986

16. Schumacher HW, Wassmann H, Podlinski C: Pseudomeningocele of the lumbar spine. Surg Neurol 29:77-78, 1988

17. Solomon P, Sekharappa V, Krishnan V, David KS: Spontaneous resolution of postoperative lumbar pseudomeningoceles: A report of four cases. Indian J Orthop 47:417-421, 2013

18. Swanson HS, Fincher EF: Extradural arachnoidal cysts of traumatic origin. J Neurosurg 4:530-538, 1947

19. Teplick JG, Peyster RG, Teplick SK, Goodman LR, Haskin ME: CT identification of postlaminectomy pseudomeningocele. AJR Am J Roentgenol 140:1203-1206, 1983

20. Weng YJ, Cheng CC, Li YY, Huang TJ, Hsu RWW: Management of giant pseudomeningoceles after spinal surgery. BMC Musculoskelet Disord 11:53, 2010

\section{Disclosures}

The authors report no conflict of interest concerning the materials or methods used in this study or the findings specified in this paper.

\section{Author Contributions}

Conception and design: Vanni, Urakov. Drafting the article: Alvarez, Urakov. Critically revising the article: Alvarez, Urakov. Reviewed submitted version of manuscript: Alvarez, Urakov. Approved the final version of the manuscript on behalf of all authors: Vanni.

\section{Correspondence}

Steven Vanni, University of Miami Hospital, 1321 NW 14 St., Ste. 306, West Miami, FL 33125. email: svanni@med.miami.edu. 